\title{
Özgün Çalışma
}

\section{Hodgkin Lymphoma Treatment; What Has Changed in the Last 30 Years}

\author{
Hodgkin Lenfoma Tedavisi; Son 30 Yılda Neler Değişti \\ Mehmet Faik Çetindağ \\ Medipol Mega Üniversite Hastanesi İstanbul
}

\begin{abstract}
Introduction: In this study, based on the Hodgkin lymphoma thesis made in 1990, current developments in Hodgkin lymphoma diagnosis, imaging and treatment are examined with case samples. Changes in treatment indication in the last 30 years, shrinkage in radiotherapy treatment areas and radiotherapy dose reductions are evaluated comparatively, taking into account historical processes.

Methods: The demographic and clinical characteristics of the patients whose treatment was completed in the radiotherapy clinic of Ankara Numune Hospital between 1985-1990 will be summarized and the current imaging methods and treatment approaches at that time are compared with current approaches.

Results: The data of 60 cases treated with the diagnosis of Hodgkin lymphoma in Ankara Numune Hospital between 1985-1990 are analyzed. The median age was 31. Histologic types and stages are distributed evenly between the groups. The initial involvement areas are such that; 34 cases start in the cervical-supraclavicular region (56\%), eight in inguinofemoral (13\%), seven in axillary (11\%), five in mediastinal (8.2), three in the abdominal (5.3\%), two in the tonsillar (3\%), one in primary cerebral. Diseases that initiated under the diaphragm were $18 \%$ of the total. Mixcellular type constituted the most common group. In the 1980s, the standard treatment method for Stage IA and II A Hodgkin lymphoma was Sub Total Lymphoid Irradiation (Mantle, Inverted Y). In this period, the most advanced technique used in Hodgkin lymphoma imaging was Bi-Pedal Lymphangygraphy, while FDG PET-CT is the primary imaging method today. In this study, the number of recurrent patients is to be found 6 out of 58 who received radiotherapy. Four of them were outside the field, and two were within.

Discussion and conclusion: The excessive number of out of field recurrences, side effects such as growth and development retardation, cardiac problems, and increase in secondary cancers caused (especially in the childhood age group) by wide-field radiotherapy applications; led researchers to seek new treatment modalities. Nowadays, applications of radiotherapy with reduced size and decreased dose combined with better chemotherapy practices. While improvements in both chemotherapy and radiotherapy techniques have increased the 5-year life above 90\%, morbid side effects have remained anecdotal in historical articles.
\end{abstract}

Keywords: Hodgkin lymphoma, radiotherapy, chemotherapy

\section{ÖZET}

Giriş ve amaç: $\mathrm{Bu}$ çalışmada 1990 yılında yapılmış Hodgkin lenfoma tezinden yola çıkılarak günümüzde HL tan1, görüntüleme ve tedavi sindeki güncel gelişim vaka örneklemleri ile incelenecektir. Son 30 yıldaki tedavi endikasyonu değişimleri, radyoterapi tedavi alanlarındaki küçülmeler ve radyoterapi doz düşümleri tarihsel süreçler dikkate alınarak karşılaşmalı olarak değerlendirilecektir.

Yöntem ve gereçler: Yazarın 1985- 1990 yıları arasında Ankara Numune Hastanesi Radyoterapi Kliniğinde tedavisi tamamlanan hastaların demografik ve klinik, özellikleri özetlenecek ve o tarihteki güncel görüntüleme yöntemleri ve tedavi yaklaşımları, günümüzdeki yaklaşımlarla kıyaslanacaktır.

Bulgular: 1985-1990 yılları arasında Ankara Numune Hastanesinde Hodgkin lenfoma tanısı ile tedavi edilen 60 vakanın verileri incelenmiştir. Ortanca yaş 31 olarak bulundu. Evre ve histolojik tip gruplar arasında eşit olarak dağılmıştı. Başlangıç tutulum alanlar; servikal-supraklavikular bölge 34 vaka (\% 56), inguinofemoral 8 vaka (\%13), aksiller 7 vaka (\%11), mediastinal 5 vaka $(\% 8,2)$, abdominal 3 vaka 
$(\% 5,3)$, tonsil 2 vaka (\%3), primer beyin 1 vaka olarak görüldü. Diafram altı başlayan vakalar totalin \% 18 lik bölümüydü. Miks sellüler tip en çok görülen gurubu oluşturdu. Bin dokuz yüz seksenli yı1larda Evre IA ve II A Hodgkin lenfoma da standart tedavi şekli Sub Total Lenfod Işınlama (Mantle, Inverted Y) idi. Bu dönemde Hodgkin lenfoma görüntülemesinde kullanılan en gelişmiş yöntem Bi-Pedal Lenfanjigrafi iken günümüzde FDG PET-CT primer görüntüleme yöntemidir. Bu çalışmada radyoterapi alan 58 hastanın 6 sinda yineleme olmuştur. Yinelemelerin 4 ü alan dışı, 2 si alan içi olarak raporlanmıştı Tartışma ve sonuç: Alan dışı nükslerin fazlalığı ve geniş alan radyoterapi uygulamalarının özellikle çocukluk yaş grubunda oluşturduğu büyüme gelişme gerilikleri, kardiak sorunlar, ikincil kanserlerin artışı gibi yan etkiler araştırmacıları yeni tedavi şekilleri aramaya yöneltmiştir. Günümüzde giderek boyut olarak küçülmüş ve dozu azaltılmış radyoteapi uygulamaları iyi kemoterapi uygulamaları ile eşleştirilmiştir. Hem kemoterapideki iyileşmeler hem de radyoterapi tekniğindeki gelişmeler 5 y1llık yaşamı $\% 90$ seviyelerinin üzerine çıkarırken morbid yan etkiler tarihsel makalelerde anekdot olarak kalmıștır.

Anahtar Kelimeler: Hodgkin lenfoma, radyoterapi, kemoterapi

\section{Giriş:}

Bu çalışmada 1990 yılında yapıllmış uzmanlık tezi temel alınarak, aynı yazarın tarihsel süreç içerisinde Hodgkin lenfoma (HL) radyoterapi (RT) uygulamalarındaki gelişimi irdelenecektir. HLRT uygulamaları geniş alanlardan; [Total Lymphoid Irradiation (TLI), Sub-Total Lymphoid Irradiation (STLI), (Extended Mantle, Mantle, Inverted Y, para-aortik+ dalak)], dar alanlara; (Involved Field (IFRT), Involved Site RT (ISRT), Involved Lymph Node RT (ILNRT)] evrim geçirmiştir. Immunofenotipik özelliklerin rutine girmesi ile 4 alt tipi olan klasik sınıflamaya; (Lenfosit fakir, lenfosit zengin, noduler sklerozan, miksselüler), ek CD 30 - CD 45, CD 45 + CD 20 + CD 79a + özelliklere sahip ikinci bir grup; (nodüler lenfosit baskın HL) eklenmiştir. Klasik HL'da bugün için kabul edilen tedavi kemoterapi (KT) sonrasinda ISRT ve INRT ile sınırlanmıştır. Noduler lenfosit baskın HL sadece RT ile tedavi edilebilir. HL'nın önceden tahmin edilebilir bir şekilde sıralı lenf nodu bölgelerini tutacağı varsayımından hareketle, geçmişte evre IA ve IIA hastalar KT almadan sadece TLI veya STLI ile tedavi edilmişlerdir. Günümüzde HL \%90'ların üzerinde kür şansına sahip olup yeni çalışmalar kür şansını artırmaktan çok yan etki ve toksisiteyi azaltmak üzerine bina edilmektedir (1-4). Çocukluk çağında radyoterapinin geri dönüşü olmayan hasarlara, büyüme gelişme geriliklerine ve ikincil kanserlere yol açacağı bilindiğinden düşük doz RT ile kemoterapi kombinasyonları erişkin yaş grubuna göre çocukluk yaş grubunda çok daha erken yol almıştır.

\section{Bulgular:}

Yazarın 1990 yılında yaptığı bitirme tezinde 1985-1990 y1lı arasında Ankara Numune Eğitim ve Araştırma Hastanesinde tedavi edilen HL tanilı 60 hasta incelenecektir. Hastaların 23'ü kadın ve 37'si erkek idi. Erkek kadın oranı 1.6/1 olarak bulundu. Yaş dağılım grafiğindeki pik 20-30 yaş grubunda görüldü (vakaların \%21) ve ortanca yaş 31 olarak bulundu. Dikkati çeken diğer bir grup 0 -10 yaş grubu idi. Tüm vakaların \%10'u bu grup içinde yer ald1. 30-40 yaş grubu $\% 16$ ve diğer dekatlarda 60 yaşına kadar \%7-10 arasında dengeli bir şekilde dağılmıştı. Histopatolojik dağılım önemli bir özellik arz etmemektedir. Mikssellüler tip \%27, lenfosit zengin tip \%21,6, noduler sklerozan tip \%21,6 ve lenfositten fakir tip $\% 7$ oranında yer almaktadır. Lenfosit fakir tip erkeklerde 6/1 oranında bariz şekilde fazla idi. Vakaların evrelere göre dağılımı Evre I \%21, Evre II $\% 30$, Evre III \%21,6, Evre IV \%26,6 olarak bulundu. Vakaların 12'sinde B semptomları saptand1 (\%29). İleri evrelerde B semptomları daha sıklıkla görüldü. İleri evrede erkek kadın oranı 13/3 gibi dikkat çekici idi. Tutulum ve başlangıç bölgeleri incelendiğinde servikalsupraklavikular bölge 34 vaka (\%56), inguinofemoral 8 vaka (\%13), aksiller 7 vaka (\%11), mediastinal 5 vaka $(\% 8,2)$, abdominal 3 vaka (\% 5,3), tonsil 2 vaka (\%3), primer beyin bir vaka olarak görüldü. Diafram altı 


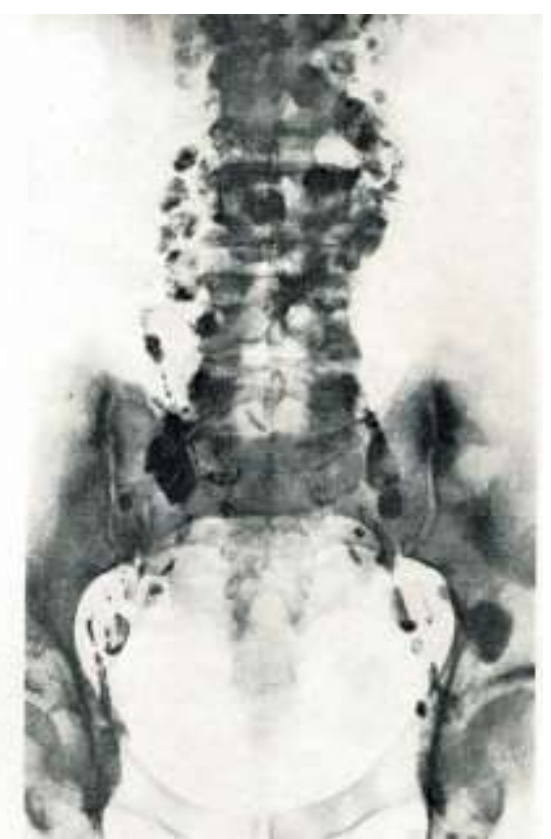

Şekil 1 Bipedal lenfanjiografi ile Hodgkin lenfoma pelvik-paraaortik tutulumu

başlayan vakalar totalin \% 18'lik bölümünü oluşturdu ve mikssellüler tip baskın olarak bu grupta yer aldı. Noduler sklerozan tip vakaların \%23'ünü oluşturdu ve primer mediastinal başlangıçlı olması dikkat çekici idi. Organ tutulumları irdelendiğinde dalak 11 vaka $(\% 18,4)$, akciğer 7 vaka $(\% 11,6)$ karaciğer 5 vaka $(\% 8,4)$, kemik iliği 2 vaka $(\% 3,3)$, kemik metastazı, tiroid invazyonu ve beyin tutulumu birer vakada izlenmiştir. 1985-1990 yılları arasında en değerli evreleme yöntemi olarak bipedal lenfanjiografi (Şekil 1), evreleme laporotomisi ve karaciğer dalak sintigrafileri kullanılmakta iken komputerize toraks ve abdominal tomografilere ulaşmak çok sınırlı vakalarda mümkün olmakta idi. Akciğer tutulumunda toraks tomografileri ve ön arka ve yan akciğer grafileri yararlı olmuştur. Dalak tutulumu 3 vakada evreleme laparotomisi ile histopatolojik olarak, 2 vakada karaciğer-dalak sintigrafisi yardımı ile konulmuştur. Karaciğer tutulumları da sintigrafi, ultrason, laparotomi ve tomografi bulgularıdır. Tiroit ve beyin tutulumları histopatolojik tanıdır. 60 hastanın 58'ine RT uygulanmıştır. 27 vaka sadece RT ile tedavi edilirken (\%50), 23 vaka çeşitli KT kombinasyonları ile birlikte RT almıştır (\%43). Radyoterapi dozu 13-40 Gy

\section{Skor Pet/CT sonucu \\ 1 Tutulum yok (no uptake) \\ 2 Tutulum $\leq$ mediasten \\ 3 Tutulum > mediasten < karaciğer \\ 4 Tutulum karaciğerden hafifçe fazla \\ 5 Tutulum karaciğerden oldukça fazla ve/veya yeni lezyon varlığı \\ Tablo 1 PET/CT Deauville kriterleri}

arasında değişmekte olup ortanca 36 Gydir. Kalan 2 vaka sadece KT almıştır. TLI olarak kabul edilen vakaların büyük kısmı patchwork (yama işi) olarak bilinen küçük birçok alanın toplamı şeklinde uygulanmıştır. TLI yapılan vaka sayısı 9 dur. Tutulmuş alan ve dalak 1şınlaması yapılan vaka sayısı 32'dir. 12 vakada mantle, 5 vakada ters $Y$ tedavi şekli uygulanmıştır. Kemoterapi uygulanan hastalarımızda 3 MOOP, 17 COPP, 4 ABVD protokolü uygulanmıştır.

Erken yan etkiler 15 vakada ciddi nötropeni, 7 vakada II. derece radyodermit, 3 vakada ciddi enfeksiyon, 2 vakada varisella zoster (zona) enfeksiyonu, bir vakada yaygin herpetik lezyonlar, bir vakada özafajit, olarak raporlanırken; geç yan etkiler bir vakada periferik sinir paralizisi, bir vakada lösemik transformasyon, bir vakada testisde kronik lenf ödem, bir vakada malign lenfoma dönüşümü olarak kayda alındı. Lösemik dönüşüm olarak raporlanan hasta RT almamıştı ve ABVD KT'sinin 8. ayında bu dönüşüm gerçekleşti ve hasta kaybedildi. Transfüzyon gerektiren hasta sayis 18 olup kombine tedaviler sirasinda 3 hasta enfeksiyon sonucu kaybedilmiştir. Servikal, mediasten ve aksilla tutulumlu bir hastamız 20 haftalık gebe idi. Tüm batın kurşun koruması ile tutulmuş alan $13 \mathrm{~Gy}$ uygulandı. Yapılan hesaplamada fetüs dozunun 2 cGy altında olduğu belirtildi.

Hastalık yinelemesi görülen 6 hastanın 4 ünde nüks alan dişı ve 2 sinde alan içi idi. Nüks görülen hastaların 2'si akciğer komplikasyonlarından, 1'i ise yaygın HL tutulumu ve çoklu organ yetmezliğinden kaybedilmiştir. Diğer 3 vaka değişik tedavi modaliteleri ile tekrar remisyona girmiştir. 


\begin{tabular}{|c|c|c|c|}
\hline Risk faktörleri & GHSG & EORTC & $\mathrm{NCCN}$ \\
\hline Yaş & & $>=50$ & \\
\hline \multicolumn{4}{|l|}{ Histoloji } \\
\hline $\begin{array}{l}\text { ESR ve B } \\
\text { semptomları }\end{array}$ & $\begin{array}{l}>50 \text { eğer } A \\
\text { semptom var } \\
\text { ise; >30 } \\
\text { eğer B } \\
\text { semptom var } \\
\text { ise }\end{array}$ & $\begin{array}{l}>50 \text { eğer } A \\
\text { semptom var } \\
\text { ise; >30 eğer B } \\
\text { semptom var ise }\end{array}$ & $>50$ veya herhangibir $B$ semptom varlığı \\
\hline $\begin{array}{l}\text { Mediastinal } \\
\text { kitle genişliği }\end{array}$ & $\begin{array}{l}\text { MMR } \\
\text { (mediastinal } \\
\text { kitle oranı) } \\
>0,33\end{array}$ & $\begin{array}{l}\text { MTR } \\
\text { (mediastinal } \\
\text { torasik oran, } \\
\text { genellikle en } \\
\text { geniş yer T5-60) } \\
>0,35\end{array}$ & $M M R>0,33$ \\
\hline $\begin{array}{l}\text { Nodal tutulum } \\
\text { sayısı }\end{array}$ & $>2$ & $>3$ & $>3$ \\
\hline $\begin{array}{l}\text { Ekstra lenfatik } \\
\text { tutulum }\end{array}$ & $\begin{array}{l}\text { Herhangibiri } \\
\text { nin varlığı }\end{array}$ & & \\
\hline $\begin{array}{l}\text { Büyük hacimli } \\
\text { tümör }\end{array}$ & & & $>10 \mathrm{~cm}$ \\
\hline
\end{tabular}

Tablo 2 Klasik HL kötü prognoz risk faktörleri. GHSG, EORTC, NCCN çalışma grupları

Hasta izlemi ortalama 30 ay idi (en az 2 ay en fazla 72 ay). İzlem sırasında 10 hasta yaşamını yitirdi $(\% 16,6)$. Halen tedavileri devam eden 3 vaka dişında $47(\% 78,3)$ hasta remisyondadir.

Tanı ve Görüntüleme:

HL tanıs1 eksizyonel biopsi (tercih edilir) veya kor biopsi ile konabilir. İnce iğne aspirasyon biopsisi yetersizdir(1-4). Tanı konulduktan sonra tüm ilgili branşların hastayı birlikte görüp değerlendirmeleri gerekir. Ulaşılabilirse kontrastlı tomografilerin yanı sira PET/CT ve özel durumlarda PET/MRG, mümkünse radyolojik kalite standartlarında kontrastlı BT ve MRG ile birlikte elde edilmelidirler. PET/CT için Deauville kriterleri Tablo 1 de verilmiştir (Tablo 1 PET/CT Deauville kriterleri). Bu kriterlere HL ile uğraşan hekimlerin aşina olması gerekmektedir. İlk görüntülerin radyoterapi planlama pozisyonlarında elde edilmesi kemoterapi sonrası tutulmuş alan ve lenf nodlarının planlama tomografisi ile yapılacak füzyonlarında kolaylık ve tedavi alan doğruluğu sağlayacaktır. Bunun için klinikler arası iyi koordinasyon ve işbirliği içinde protokoller hazırlaması şarttır. İyi fizik muayene yapılmalı, B semptomları sorgulanmall, KCFT, LDH, CBC rutin olarak istenmelidir. Özellikle doğurganlık çağ 1 öncesi vakalarda fertiliteyi koruyucu aktif ve pasif önlemler alınmalı ve hasta ve hasta sahipleri konu hakkında açık ve detaylı olarak bilgilendirilmelidir (5).

Risk Faktörleri:

Erken evre (I ve II) HL risk faktörlerinin tanımı üzerine tam bir konsensus olmamasına karşın üç ana çalışma grubu, GHSG (German Hodgkin Study Group), EORT (Europian Organization for the Research and Treatment of Cancer), NCCN (National Comrehensive Cancer network) ufak tefek ayrımlarla HL hastalarını daha kolay tedavi edilebilir (favorable) ve tedaviye daha dirençli grup (unfovarable) olarak ikiye ayırmışlardır. Tablo 2 de gösterilmiştir. 


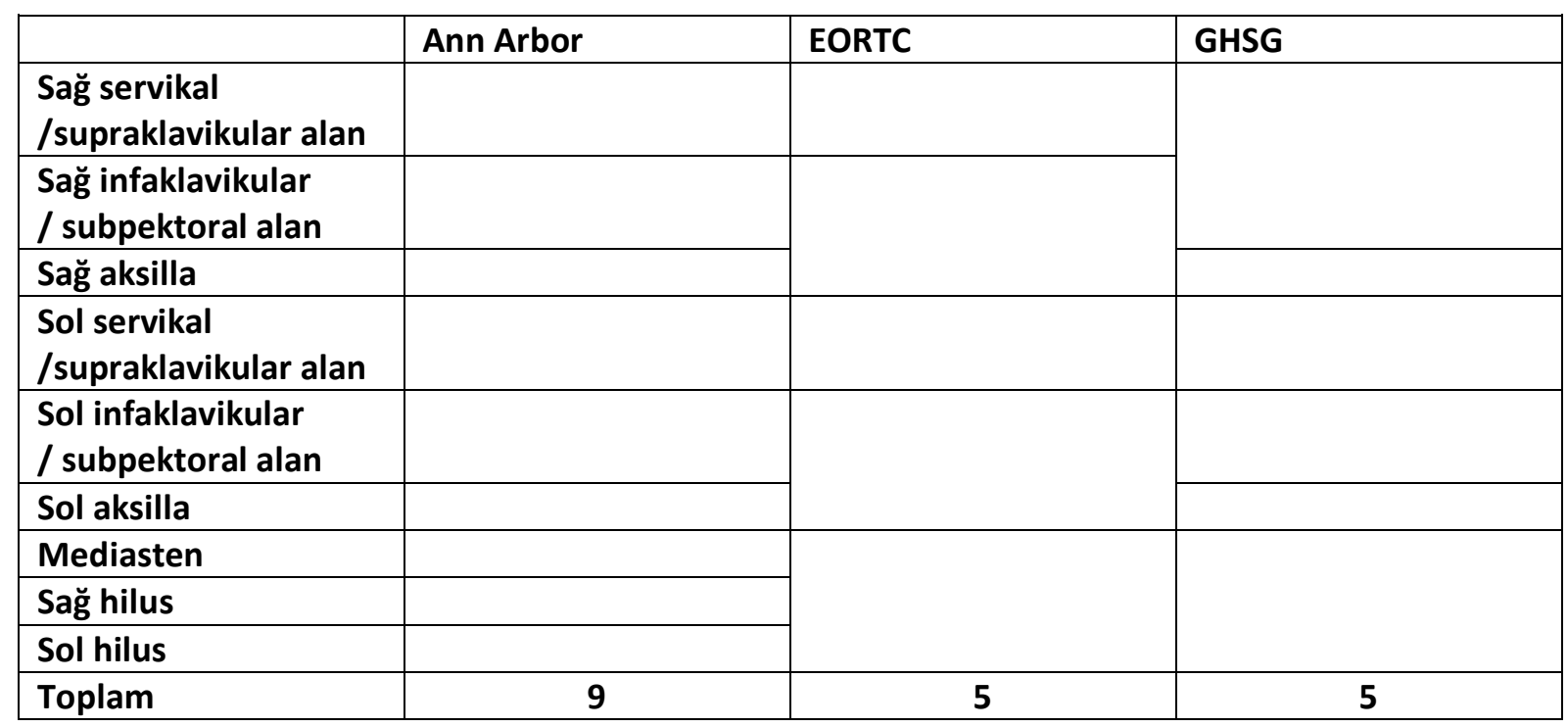

Tablo 3 Lenf nodu bölgelerinin çeşitli çalışma gruplarına göre ayrışması

İleri evre hastalıkta kullanılan IPS (International Prognostic Score) skorlama sisteminde her bir faktör 1 sayısı kabul edilerek hesaplanır (6);

- $\quad$ Albümin $<4 \mathrm{~g} / \mathrm{dl}$,

- Hemoglobin $<10.5 \mathrm{~g} / \mathrm{dl}$,

- $\quad$ Erkek cinsiyet,

- $\quad$ Yaş $>=45$,

- $\quad$ evre 4 hastalık,

- $\quad$ lokosit sayıs1 > 15000,

- $\quad$ Lenfosit sayıs1 $>600$ veya beyaz küre sayısının $\% 8$ inden az olması

Lenf nodu bölge tanımlarında da Ann Arbor siniflamasi ve EORTC ve GHSG arasinda farklılıklar vardır. EORTC infraklavikular ve subpektoral alanları aksillaya dahil ederken, GHSG bu alanları servikal bölgeye dahil ediyor. Hem EORTC hem de GHSG hiler lenf nodlarını ayrı alan olarak belirtmeyip tek mediasten bölgesi tanımlıyor(1-4 ) Tablo 3.

Tedavi şekilleri:

İki boyutlu RT:Üç boyutlu planlamalar öncesi konvansiyonel simülatör cihazları ile kemik referans noktaları üzerinden yapılan alan belirlemeleri ile uygulanan RT. Doz ölçümleri santral aks denilen tek merkez noktada yapılır ve tümörde oluşan doz değişimleri tahminen bilinirdi.
3-D Konformal: Radyoterapi: Konformal kelime anlamı saran sarmalayan demektir. Radyoterapi hedef hacimleri ICRU 62 de tanımlanmıştır. (Şekil 2) Tomografi cihazlarının RT planlama alanına girmesi ile tümör hacimleri daha iyi belirlenip çok alanlı tedavi planlamaları sayesinde target hacimler daha iyi kapsanır olmuşlardır. Bu planlamalarda 3-boyutlu olarak reçete edilen dozun hedef hacmi kapsayıp kapsamadığı Doz Volüm Histogramları (DVH) denilen bir eksende hedef ve kritik organ hacmini diğer eksende de dozu gösteren iki boyutlu grafiklerde izlenebilirler. (Şekil 3) Konformal tedavi tekniği ile 1,8x12 frk da 21,6 Gy ışınlanan hastanın Doz Volum Histogramı. ISRT-Invoved Site RT, YART: Yoğuluk Ayarlı RT IG-IMRT: Image Guided Intensity Modulated RT) Yoğunluk Ayarlı Radyoterapi (YART-IMRT): Çoklu alanların optimizasyonu sayesinde target volümler çok daha iyi kapsanırken kritik organ dozları da istenilen düşük seviyelerde tutulabilmektedir. Görüntü Rehberliğinde Radyoterapi (IGRT): Tedavi edilen bölgenin her tedavi seans1 öncesi elde edilen üç boyutlu görüntüleri ile planlamadan gelen görüntüler karşılaştırılarak eşleştirme yapılıp tedavinin doğru hedeflere 


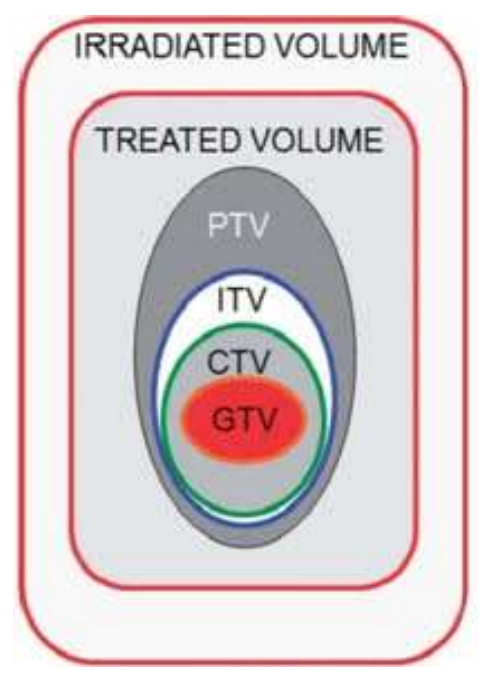

Şekil 2. ICRU 62 de tanımlanan hedef hacimler GTV: Gros Tümör Volüm, CTV: Klinik Target Volüm, ITV: İnternal Target Volüm, Planlanan Target Volüm, TV: Tedavi Edilen Volüm, IR: Işınlanan Volüm

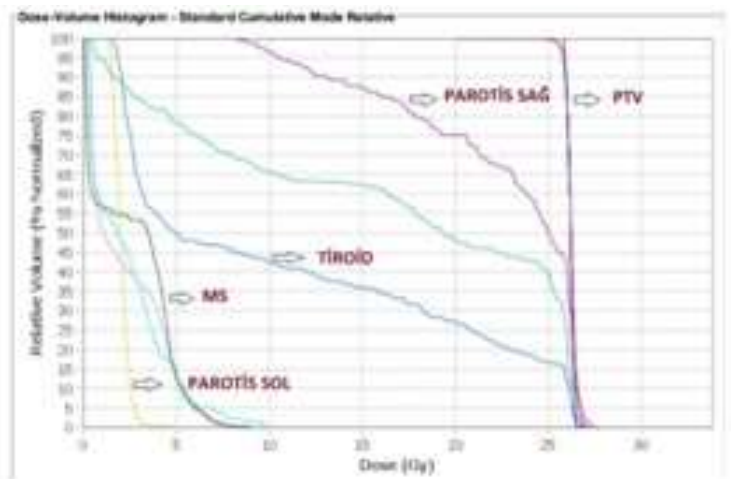

Şekil 3 Erken evre HL tutulmuş alan sağ boyun YART (IGา-IMRT

yönlendirebilmesi işlemidir. (Şekil 4)

Radyoterapi planlamalarının doğru bir şekilde yapılabilmesi için tanı anında elde edilmiş olan PET/CT, kontrastll boyun, torakal ve tüm batın tomografileri şarttır. $\mathrm{Bu}$ görüntüler steroid bile başlanmadan, mümkünse radyoterapi planlamalarına benzer pozisyon verilerek elde edilmelidir. Evreleme aşamasında PET/BT'nin tartışmasız üstünlüğü vardır (8-11). Tedavi eden ve görüntü sağlayan klinikler arsında PET/BT ve tomografi çekimleri için daha önceden yapılmış protokoller doğru füzyon yapmanın dolayısı ile tutulmuş alanların çok daha iyi belirlenmesi için anahtar rolündedir.

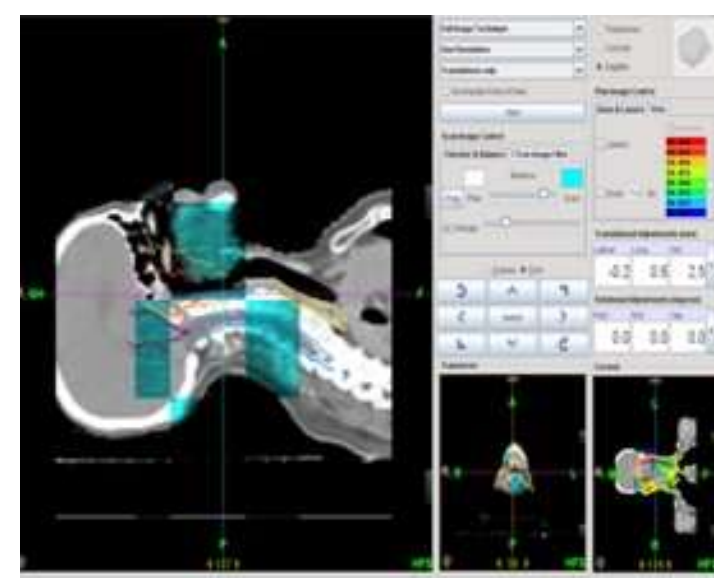

Şekil 4 Boyun tutulumlu hastada megavoltaj ct ile yapılan eşleştirme

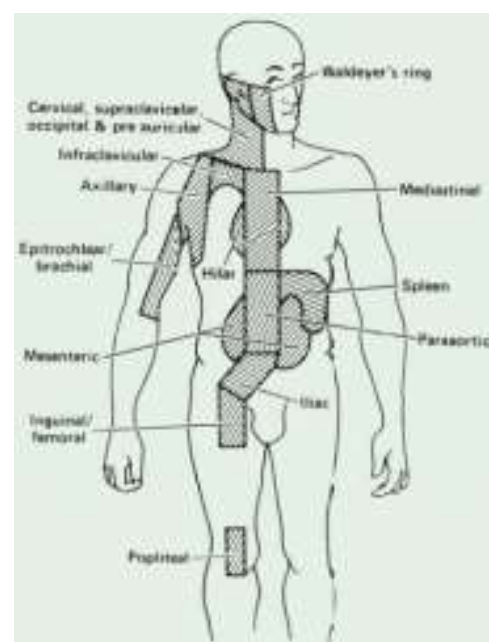

Şekil 5 Ann Arbor lenfatik bölgeleri

RT Planlamada Pozisyon

Eğer aksiller bölge 1şınlanacaksa kollar akimbo pozisyonunda yana omuz 45 derece açık eller bel hizasında olmalıdır. Eğer aksiller bölge 1şınlanmadan sadece mediasten 1şınlanacaksa ve IMRT ve Rapid ARC gibi teknikler kullanılacaksa akciğer bordu kullanılarak ellerin baş üzerine alınması önerilir. Baş maskesi kullanılması durumunda ellerin yanda olması hasta konforu açısından önemlidir. Mediastinal tutulumlu vakalarda derin inspriumda nefes tutulması akciğer hacmini arttırıp, kalbi ve akciğer parankimini alan dişına çıkarılabilir. Batın ve akciğer bölgesi 1şınlamalarında 4-D CT kullanılarak 


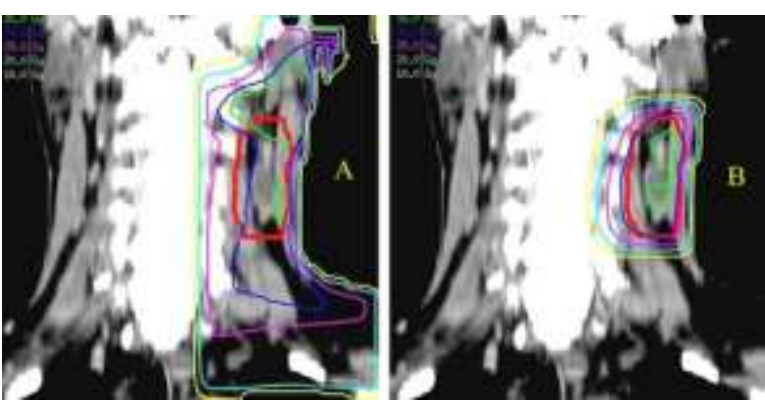

Şekil 6 A IFRT, Şekil 6 B INRT
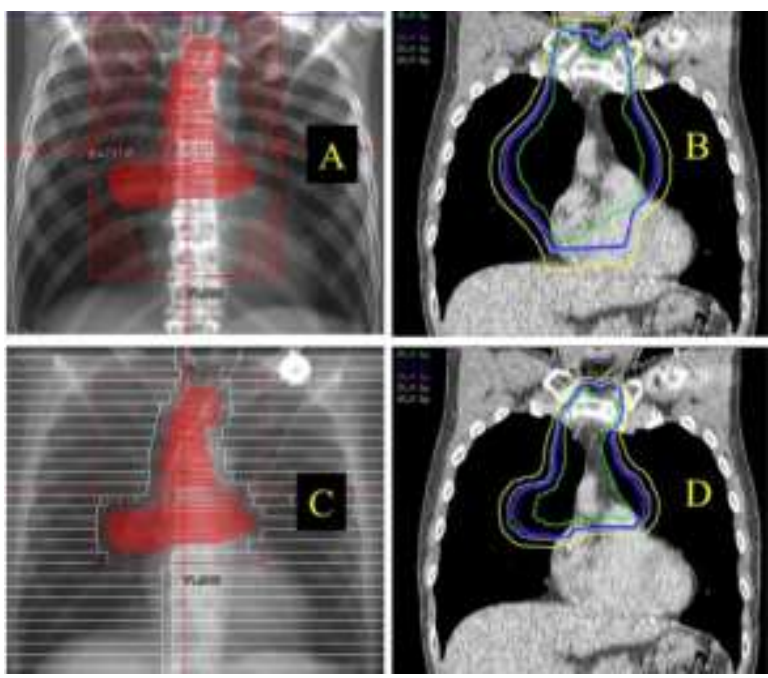

Şekil 7 A-B Mediasten tutulumlu HL IFRT ve Şekil 7 C-D ISRT

ITV hacimleri kesin doğrulukla saptanabilir. Planlama CT çekiminde kontrast kullanımı ile KT sonrası küçülmüş lenfatik grupları daha iyi tanınıp KT öncesi imajlarla doğru bir şekilde eşleştirilebilir (1-4).

Total Nodal Işınlama (TNI- Total Nodal Irradiation):

Kemoterapi öncesi dönemlerde kullanılırdı. Tüm majör lenfatikler alan içerisine alınır. Geniş bir alan 1şınlama olacağından genellikle 2 bölüm halinde önce mantle sonra ters $\mathrm{Y}$ ve dalak ışınlaması yapılır. Bazı lenfatik bölgeler alan dişında kalır (mezenterik lenf nodları gibi). Tarihsel önemi vardır.

Geniş Alan Işınlama (EFRT- Extended-FieldRadiotherapy):

$\mathrm{Bu}$ 1şınlama alanında tutulmuş bölge yanı sıra komşu birinci ve ikinci bölge lenfatikler de alan içerisine alınır. Bu ışınlama HL'nın non Hodgkin lenfoma aksine lenfatik bölge sirası takip ettiği ve sira atlayarak (skip) metastaz yapmayacağı varsayımına dayanmaktadır. Etkin KT protokolleri sayesinde bu alanların kullanımı günümüzde çok azalmıştır. Tarihsel süreç içerisinde evre IA ve IIA diafram üstü tutulumlarda mantle + çöliak + dalak olarak uygulanmıștır. Diafram altı başlayan daha az vaka da ise ters-Y ve dalak 1şınlaması şeklinde uygulanmıştır.

Tutulmuş alan 1şın tedavisi (IFRT- İnvolvedField-Radiotherapy):

Daha çok sınırlandırılmış hastalıkta kullanılan bir tekniktir. Çok yaygın kullanılmasına rağmen net bir tanımı yoktur. Kullanımı RT'nin iki boyutla yapıldığı dönemlerden kalmış olması nedeni ile alan konumlanmasında Ann-Arbor siniflamasinda belirtilen bölgeler kullanır (Şekil 5). Gruplar arsında lenf bölgelerinin tanımı konusunda da tam bir fikir birliği yoktur. Bu yüzden her klinikçe farkl1 uygulamalar olabilmektedir. Hastalık hangi nodal bölgeyi tutuyorsa o bölge lenfatikleri alan içine alınır. Örneğin supraklavikuler bir lenf nodu tutulumunda o taraf boynun tamamı veya mediasten tutulumunda mediastenin tamamı alan içerisine alınır. (Şekil 6 A-B) Ekstranodal tutulumlarda ise ekstranodal bölge ve birinci komşu lenfatikler alan içerisine alınır. KT etkinliği arttıkça 1şınlanan RT hacimleri giderek küçülmüş ve tutulu olmayan lenfatik bölgelerdeki mikroskobik yayılımlar için RT etkinliği önemini yitirmiştir (7).

Tutulmuş Yer Radyoterapisi (ISRT-involved site radiotherapy): RT verilmeden sadece KT ile HL tedavisi çalışmalarından istenilen sonuçlar alınamamıştır $(8,9)$. Günümüzde çocuk hastalar da dâhil olmak üzere RT ihtiyacı ortadan kalkmamıştır. Ancak yapılan çalışmalarla alanların küçülmesinin tedavi etkinliği üzerinde bir rol oynamadığı ortaya konmuştur. Özellikle düşük riskli gruplarda kullanılan KT protokol ve sayısı ile bağlantılı olarak alan daralmasının yanı sıra RT dozları da giderek azaltılmıştır. Böylece RT morbidite ve geç yan etkilerinin azaltılması amaçlanmıştır. International Lymphoma Radiation Oncology Group (ILROG) Lenfoma ve RT için ISRT rehber kitapcığını (guideline) yayınlamıştır. IFRT de Ann Arbor sinıflamasında tariflenen lenfatik bölgeler iki veya üç boyutlu olarak ışınlanırken, ISRT'de 
o bölgenin tutulu kısmı mümkün olan en iyi konformal teknikle ışınlanmaktadır (Şekil 7 A B C D). ISRT görüntü rehberliğinde konformal RT tekniklerinin klinik uygulama alanına girmesi ile uygulanabilir olmuştur. IFRT uygulamaları sirasinda ICRU; GTV, CTV, ITV, PTV tanımlamalarını henüz yapmamışt1. Bu nedenle IFRT Ann-Arbor lenfatik bölgeleri referans alınıp, konvansiyonel simülatörler üzerinden yapılan tedavi olarak tarihsel süreçte yerini almıştır. ISRT de ise tutulu lenf nodları kemoterapi öncesi CT, PET/CT de tanımlanıp planlama tomografisi ile yapılan füzyonlarda bu lenf nodlarındaki gerileme ve küçülmeler dikkate alınarak kemoterapi sonrası CTV'ler elde olunur. Klinik ve hastadan hastaya değişmekle birlikte oluşturulan CTV ler her yöne $1 \mathrm{~cm}$ genişletilerek elde olunan PTV lerle yapılan tedavidir (8-15).

Tutulmuş Lenf nodu RT: (INRT, involved node radiotherapy)

Grinsky ve Ark. ISRT den çok daha sık1 kriterler içeren ve tedavi öncesi planlama pozisyonunda PET/CT çekimini olmazsa olmaz şartı koydukları INRT kriterlerini bir makalede sunmuşlardır (12,16-19). Pratikte uygulama alanı bulması zor olan bir tedavi şekli olup branşlar arası sıkı koordinasyon gerekmektedir. Tutulu lenf nodu dişında herhangi bir riskli bölge 1şınlanan volüme dâhil edilmez. ISRT ile planlama aşamaları benzerlik gösterir (16-18). Protonla yapilan tutulmuş lenf nodu tedavisinin (INPRT) düşük doz integral saçılmayı azaltacağı ve dolayısı ile ikincil kanser ve kardio-toksisite gibi radyoterapinin on y1llar sonrasında ortaya çıkacak yan etkilerini önemli ölçüde engelleyeceği bilinmektedir (20-23). Eğer ulaşılabilirse özellikle çocukluk çağı HL da proton tedavisi kullanmak gereklidir.

Tedavi:

HL RadyoterapiEndikasyonları:

Noduler sklerozan predominant HL; (NSPHL)

\section{Erken Evre: Stage I-II}

Erişkin noduler lenfosit predominant HL da B semptomları yoksa evre I ve II de sadece ISRT yapılabilir. Günlük doz 1,5-2 Gy arasında olmak üzere toplam 30-36 Gy verilir.
Genellikle klasik HL da kullanılan alanlardan daha geniş alanlar kullanılır. Tutulmamış komşu alanlar için günlük 1,5-2 Gy fraksiyonlarla 25-30 Gy yeterli dozdur (2428).

Çocukluk çağında tekli lenf nodu varlığında eksizyonel cerrahi sonras1 s1k1 takip yeterli olabilir. Nüks halinde siklofosfamid/ vinblastin/ prednizolon (CVP) veya VAMP veya AV-PC (adriamisin, vinkristinprednizolon, siklofosfamid) KT protokolleri ve/veya düşük doz ISRT ile tedavi edilebilirler (27-29).

İleri evre II-IV ve veya büyük hacimli hastalık ve/veya B semptomları varlığı;

Erişkin yaş grubunda ABVD + Rituximab + ISRT, CHOP + Rituximab + ISRT, sadece rituximab veya ISRT veya ISRT'li Rituximab tedavi seçenekleri arasındadır.

Çocukluk yaş grubunda erken evre kemoterapileri ve düsük doz ISRT kullanılabilir (29). Örnek 1, Örnek 2, Örnek 3, Örnek 4, Örnek 5, Örnek 6. Örnek 7

Örnek 1: ISRT: $12 \mathrm{Y}$, erkek hasta. 3 kür ABVD sonrası belirgin regresyon, tutulu alan $1,8 \times 14$ frk da toplam 25,20 Gy konformal (ISRT) radyoterapi uyguland.

(Şekil 8: Örnek 1)

Örnek 2: IG-IMRT Para-aortik-dalak: 6 yaşında iken nazofarenks (ekstra nodal tutulum), boyun ve mediasten bölgesinde tutulumu olan Evre IIIS tanısı ile 4 kür ABVD sonrası nazofarenks boyun ve dalak bölgesine tutulmuş alan radyoterapisi alan hasta 1,5 y1 sonra para-aortik ve dalak izole nüksü ile II. Seri 6 kür ABVD sonrası dalak ve para-aortik YART tedavisi (ISRT). İlk 4 frk $180 \mathrm{cGy}$ ve sonra hemotolojik toksisite nedeni ile doz 120 cGy düşülerek toplam doz 16.8 Gy tamamlandı. Hasta 6 senedir nükssüz izleniyor. Büyüme gelişme yaşıtları ile uyumlu olup takip edilmektedir.

(Şekil 9: Örnek 2)

Örnek 3: Para-aortik ve dalak IFRT: Dalak ve para-aortik tutulumlu benzer bir hastanın konformal radyoterapi alanları (IFRT).

(Şekil 10: Örnek 3)

Örnek 4: Sol boyun mediasten ve dalak tutulumlu evre 3 HL. 4 kür ABVD) 


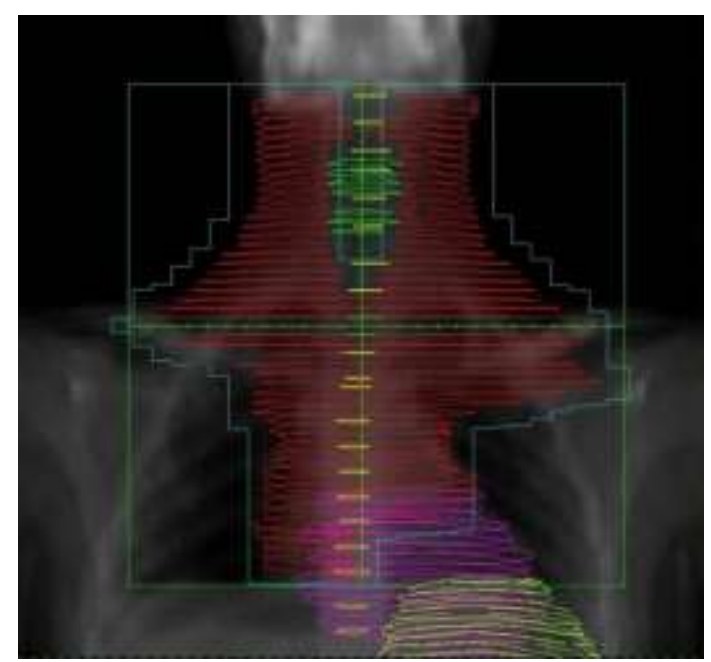

Şekil 8: Örnek 1

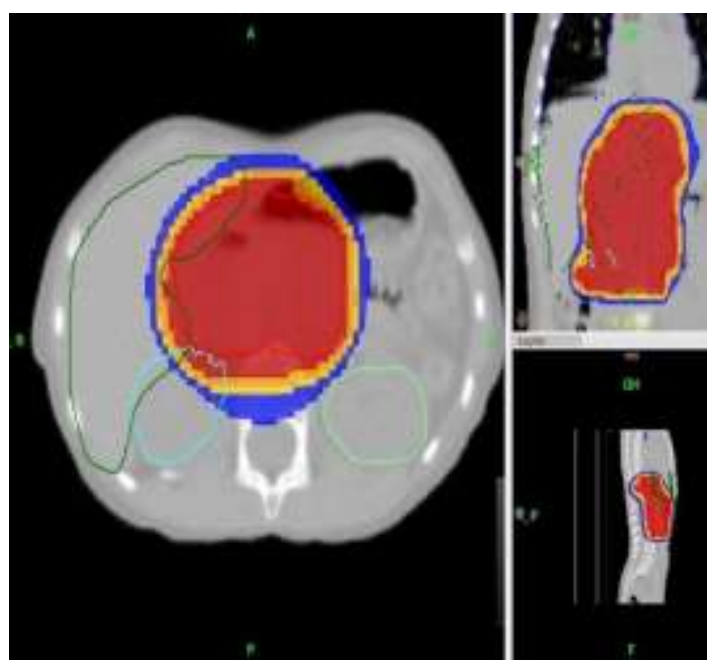

Şekil 9: Örnek 2

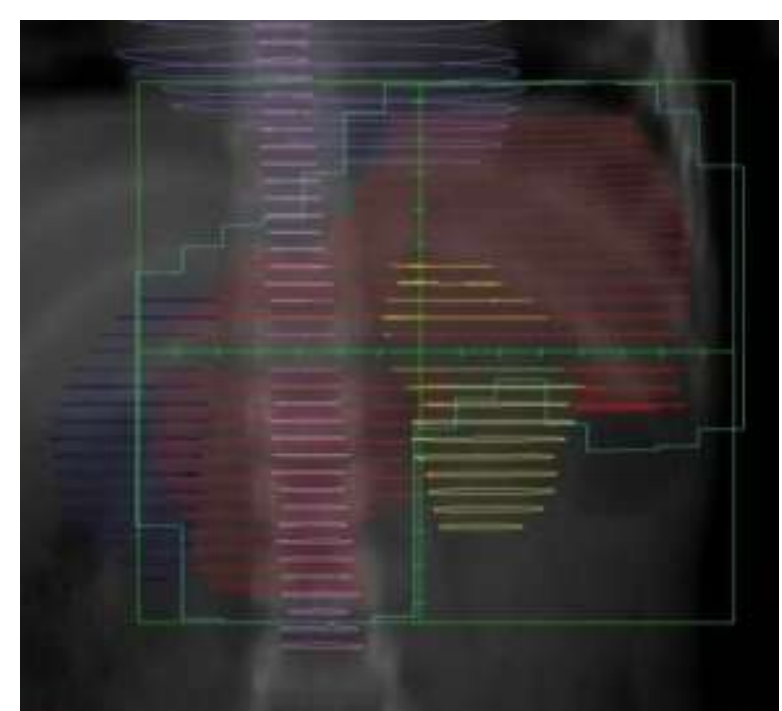

Şekil 10: Örnek 3

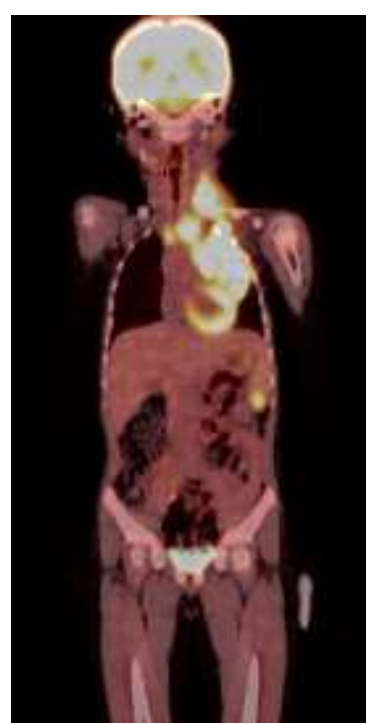

Şekil 11: Örnek 4 PET/CT 1 Tedavi öncesi

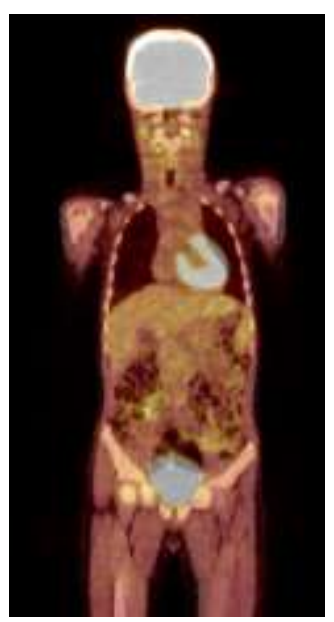

Şekil 12: Örnek 4 PET/CT 2 Tedavilere yanıt değerlendirilmesi

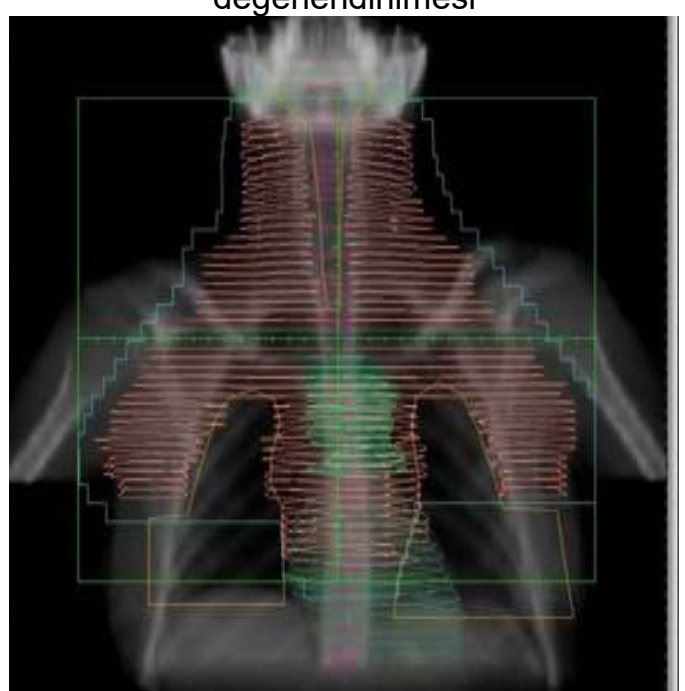

Şekil 13: Örnek 6 A 6 Mantle ışınlama 
Örnek 5: 50 y bayan hasta 5 Kür ABVD sonrasi bleomisin toksisitesi nedeni ile ileri derece akciğer toksisitesi gelişen ve PET/CT de parsiyel metabolik yanıtı olan hastaya tüm tutulum bölgelerine yönelik faz I: 1,8 Gy x 16 frk da toplam 30,6 Gy ve metabolik aktif alana yönelik faz II: 1,8x3 frk da 5,4 Gy toplam 36Gy mantle radyoterapi uygulamasi.

Mantle $=$ Bilateral servikal+ supraklavikuler + aksiller+ mediastinal+ hiler RT

(Şekil 13: Örnek 5 Mantle 1şınlama)

Klasik HL: (miksseluler, Lenfost zengin, Lenfosit fakir, Noduler sklerozan)

Erişkin çağı iyi prognoza sahip erken evre I A ve II A hastalıkta 2 kür ABVD KT sonrası elde edilen PET/CT Deauville kriterleri 1-4 arasında ise 20 Gy ISRT yeterli tedavidir. (GHSG HD 10 çalışması) (28).

Alternatif olarak evre IA-IIA düşük hacimli hastalık 3 kür ABVD sonrası PET/CT remisyon değerlemesi Deauville 1-2 arasında ise ya takip ya opsiyonel 4 küre tamamlanır. Deauville 3-4 arasinda ise ABVD 4 siklusa tamamlanır ve 30 Gy ISRT uygulanır. Eğer 2 kür ABVD sonrası remisyon değerlenmesine alınıyorsa, Deauville 1-2 arasında 3. kür ABVD sonrası 30 Gy ISRT, Deauville 3-4 ise 2 kür BEACOPP sonras1 30 Gy ISRT uygulanıyor veya alternatif olarak ABVD 4 küre tamamlandıktan sonra 30 Gy ISRT uygulanıyor. Her iki halde de Deauville 5 halinde biopsi ile hastalık teyit edilirse tedaviye refraktör hastalık sinıfına alını-yor (29).

8 haftalık Stanford V tedavisi sonrası PET/CT Deauville 1-4 ise 30 Gy ISRT uygulaniyor. (RAPID, EORTC H10, Stanford G4 çalışmalarından NCCN tarafından modifiye edilmiştir)

Erişkin çağ 1 kötü prognostik kriterlere sahip erken evre I -II hastalar 2 siklus ABVD KT sonrası remisyon değerlemesi sonrası Deauville 1-2 ise ABVD 4 küre tamamlanırsa ISRT, 6 ya tamamlanırsa ISRT opsiyon olarak bırakılabiliyor. Deauville 3-4 arasında skorlanıyorsa yine 4 kür sonrası ISRT veya 2 kür BEACOPP sonrası 30 Gy ISRT öneriliyor.

Çocukluk çağında erken evre iyi prognoza sahip hastalarda cinsiyet göz önüne alınarak risk adaptif tedaviler öneriliyor. Alkilliyeci ajan içermeyen 4 kür VAMP KT si sonrası 1525 Gy ISRT yeterli oluyor. (30-31).

Diğer başarılı sonuçlar ABVD, DBVE, AVPC, ABVE-PC KT'lerine düşük doz (21 Gy) ISRT eklenerek elde edilebiliyor. Radyoterapiyi dışlayan çalışmalar nüks oranlarının yüksekliği nedeni ile günümüzde kabul edilmiyor (29). Ancak son NCCN direktiflerinde erken evre düşük risk risk HL da 2 kür OEPA veya 3 kür AVPC sonrası tam yanıt elde edilirse tutulmuş alan yapılmayabilir (28).

Çocukluk çağı kötü prognostik kriterlere sahip erken evre veya ileri evre hastalarda 6 kür ABVD ve ISRT ile \%87 3 y1llık hastalıksız yaşam süreleri verilmiştir. Ancak bu serilerde akciğer toksisite oranları \%9 olarak raporlanmıştır. BEAC COPP sonrası toksisiteyi azaltmak amaçlı cinsiyete göre KT sınıflandırılması erkeklerde (vinkristine-etoposid) OEPA/COPDAC, kadınlarda (prokarbazin) OPPA/COPP KT protokollerine ilave 20-30 Gy ISRT ile \%97 lere ulaşan 5 yıllık yaşam sonuçları elde edilmiştir. Bu gruplarda ABVD benzeri kürler ve ISRT ile elde edilen erişkin 5 yıllık yaşam oranları \%65-75 bandında kalmaktadır. Ayrıca COG AHOD0831 numaralı çalışmanın sonuçları yayınlanırsa ABVEPC ile yüksek doz siklofosfamid ile tedavi edilen ileri evre HL hastalarının sonuçları değerlendirmeye alınacaktır. Bu grupta ISRT 14 frk da 21 Gy olarak uygulandı. Uygulama kriterleri yüksek hacimli ilk tutulum bölgeleri, yaygın dalak tutulumu, KT ye yavaş cevap alınan bölgeler ve $2,5 \mathrm{~cm}$ üzerinde rezidü içeren bölgeler olarak belirlendi (32-37).

Radyoterapi bilindiği üzere lokal ve bölgesel bir tedavi yöntemidir Günümüzde HL radyoterapisi konformal 3-boyutlu veya YART teknikleri kullanılarak tutulu alan (IFRT), tutulu yer (ISRT), tutulu nod (INRT) şeklinde uygulanabilir.

NCCN RT doz önerilerini toparlayacak olursak kombine tedavinin parçası olarak radyoterapi uygulamasında $(29,32)$;

Çocukluk yaş grubu düşük ve orta riskli gruplarda tüm tutulmuş alanlara günlük 1,5-2 gy fraksiyonlarla $21 \mathrm{~Gy}$ yeterlidir. Eğer cevap nispeten yavaş ise 9 Gy boost yapılabilir. Cevabın yeterli olmadığı vakalarda dozu 3040 Gy seviyelerine çıkarmak gerekebilir. 
Erişkin yaş grubunda ise Bulky olmayan evre IA-II A hastalarda ise ABVD sonrasi 20-30 Gy (iyi risk grubunda 20 Gy, kötü risk grbunda $30 \mathrm{~Gy}$ ), Stanford sonras1 ise $30 \mathrm{~Gy}$ olarak önerilmektedir. IB, IIB bulky olmayan hastalarda tutulmuş alan 30 Gy yeterli dozdur. Bulky hastalıkta cevaba göre 30-36 Gy verilebilir. İyi cevap vermeyen hastalarda 3645 Gy dozlara çıkmak gerekebilir.

NLPHL da kemoterapi verilmeden tutulu alanlara günlük 1,5-2 Gy fraksiyonlarla toplam 30-36 Gy, tutulu olmayan komşu bölgelere 20-25 Gy vermek yeterli olacaktır

BEACOPP kemoterapisi sonrası için önerilen RT dozu ise 30-36 Gy'dir. NLPHL hastalarinda sadece RT ile tedavi edilenlerde RT dozu 30-36 Gy'dir.

Palyasyon dozu 4-30 Gy arasında değișebilir. Tutulum olmadığı sürece tüm hastalarda yüksek servikal lenf nodları ve kadınlarda aksilla her zaman RT alanının dışında tutulmalıdır.

\section{Tartıșma:}

İki boyutlu RT'den 3 boyutlu konformal (saran-sarmalayan) RT'ye geçiş sayesinde hedef doku ve kritik organların aldığ dozlar bilgisayarlar sayesinde kolayca hesaplanabilir olmuştur. Yazarın tezini yayınladığı tarihte Türkiye'de çoğu klinikte 2 boyutlu RT uygulamada idi. Tomografi tetkiklerine çoğu hastanın ulaşma imkânı yoktu. İki boyutlu grafiler, USG, klinik muayene ve tecrübe ile hastalığın yaygınlığı saptanmaya çalışı11yordu. Çoğu zaman HL'nın sıralı lenfatik yayılma yolları izlenerek tedavi alanları oluşturuluyordu. Tedavi genellikle karşılıklı paralel alanlardan Co 60 cihazı kullanarak veriliyordu. HL evrelemesinde 'StagingLaparotomi' olarak adlandırılan morbit cerrahi işlem kullanımda idi. Evreleme laparotomisi; paraaortik LN örneklemesi KC biopsisi, splenektomi, overlerin alan dişına taşınması gibi cerrahi girişimler içeriyordu. Bu dönemde kullanımda olan ve tomografi ve MR görüntülemenin rutin kullanıma alınması ile unutulan değerli bir diğer tetkik Bipedal

\section{Referanslar}

1. Richard T. Hoppe. Hodgkin Lymphoma. In: Perez and Brady's Principles and Practice of Radiation lenfanjografi idi. Bu tetkik ile büyümüş lenf nodları iki boyutlu planlamada düz grafiler ve simülasyon filmlerinde yol gösterici oluyor ve hastaların takibi lenf nodlarındaki tutulum aylarca kaldığı için düz grafilerle yapılabiliyordu. Yoğunluk ayarlı RT ile bir sonraki aşamaya geçilmiş ve hedef dokularda doz yoğunlaştırılırken hassas dokuların dozları yan etki oluşturmayacak düzeylerin altına çekilmiştir. Yoğunluk ayarlı tedavi çoklu alanların tümörlü doku üzerinde çakıştırılması ve dozun belli bölgelerde yoğunlaştırması sayesinde olmaktadır. Cihazlardaki teknolojik gelişmeler dozun yoğunlaştırılmasına imkân sağlarken güçlü bilgisayar yazılımları bu hassas doz hesaplamalarını dakikalar içinde yapabilmektedir. Son 30 yıllık tarihsel süreçte HL tedavisinde 1 şın tedavisi hedef hacimleri giderek küçülmüş dozlar azalmıştır. KT öncesi ve sonrası FDG-PET/BT değerlendirmeleri günlük rutine girmiştir. Pet/BT sayesinde evreleme çok daha kesin olarak yapılabilmekte ve tedaviye yanit Deauville kriterleri ile standart bir şekilde değerlendirilebilmektedir. $\mathrm{Bu} 30$ yıllık süreç içinde endikasyonlarda değişmiştir. Evre I A ve IIA HL da 40 yıl önce standart tedavi olan geniş alan' Mantle Ters Y' ışınlamaları yerini II-IV kür KT sonrası tutulmuş alan veya tutulmuş lenf nodu ışınlamalarına bırakmıştır. Böylece her iki modalite en az yan etki ile bağdaştırılmıştır. Yoğunluk ayarlı tedavilerin güncel tedaviye girmesi ve daha az yan etkili KT rejimlerinin kullanılması sayesinde kalbin ve akciğerlerin maruz kaldı $\breve{g}_{1}$ toksisite minimalize edilip kalp yetmezliği, koroner kalp hastalığı ve ikincil kanserler gibi geç yan etkiler oldukça düşük seviyelere gerilemişsir. Sonuç: Tüm evreler dikkate alındığında HL 5 yıllık yaşam süresi 1990 larda \% 70'lerde iken günümüzde \%90'lara çıkmıştır. Daha da önemlisi tedavi modalitelerindeki iyileşmeler ve teknolojik gelişmelerin de yardımı ile geç yan etkiler ve ikincil kanser oluşumlarında önemli ölçüde iyileştirmeler sağlanmıştır.

Oncology. (Lww.com). Lippincott Williams \& Wilkins, a Wolters Kluwer. Philadelphia, 2013; 1531-47.

2. Monika L. Metzger, Hiroto Inaba, Stephanie Terezakis, and Louis S. Constine. Lymphomas in 
children. In: Perez and Brady's Principles and Practice of Radiation Oncology. Lww.com). Lippincott Williams \& Wilkins, a Wolters Kluwer. Philadelphia, 2019; 16951712.

3. Kenneth B. Roberts, Kara M. Kelly, and Louis S. Constine. Pediatric Hodgkin's Lymphoma. In: Guderson and Tepper, Clinical Radiation Oncology. (expert consult. inkling.com/ redeem). Elsevier, Philadelphia, 2016 ;1464-85.

4. Andrea K. Ng, Lawrence M. Weiss, and Ann S. LaCasce. Hodgkin's Lymphoma. In: Guderson and Tepper, Clinical Radiation Oncology. (expert consult.inkling.com/redeem). Elsevier, Philadelphia, 2016;1506-23.

5. Mauz-Korholz C, Hasenclever D, Dorffel W, et al: Procarbazine-free OEPA-COPDAC chemotherapy in boys and standard OPPA-COPP in girls have comparable effectiveness in pediatric Hodgkin's lymphoma: The GPOH-HD-2002 study. J Clin Oncol. 2010; 28(23):3680-3686.

6. Group E-PHsL. Recommendations for the Diagnostics and Treatment of children and adolescents with a classical Hodgkin's Lymphoma during the Interim phase between the end of the EuroNet-PHL-C1 Study and the start of the EuroNet-PHL-C2 Study. 2013; [cited 2014 January 4, 2014].

7. Engert A, Schiller $P$, Josting $A$, et al. Involvedfield radiotherapy is equally effective and less toxic compared with extended-field radiotherapy after four cycles of chemotherapy in patients with early-stage unfavourable Hodgkin's lymphoma: results of the HD8 trial of the German Hodgkin's Lymphoma Study Group. J Clin Oncol 2003; 21: 3601-8.

8. Metzger ML, Weinstein $\mathrm{HJ}$, Hudson MM, et al: Association between radio-therapy vs no radiotherapy based on early response to VAMP chemotherapy and survival among children with favorable-risk Hodgkin lymphoma. JAMA. 2012; 307 (24): 2609-2616.

9. Meyer RM, Gospodarowicz MK, Connors JM et al. ABVD alone versus radiation-based therapy in limited-stage Hodgkin's lymphoma. N Engl J Med. 2012; 366(5): 399-408.

10. Illidge T, Specht L, Yahalom J. Modern Radiation Therapy for Nodal Non-Hodgkin Lymphoma-Target Definition and Dose Guidelines From the International Lymphoma Radiation Oncology Group. IJROBP. 2014; 89 (1):49-58.

11. Girinsky $T$, van der Maazen $R$, Specht $L$ et al. Involved-node radiotherapy (INRT) in patients with early Hodgkin lymphoma: concepts and guidelines. Radiother Oncol. 2006; 79: 270-277.

12. Bradford S. Hoppe and Richard T. Hoppe. In Target Volume Delineation for Conformal and Intensity-Modulated Radiation Therapy. (www. springer. com). Switzerland, 2015; 451-64.
13. Yahalom J, Mauch P. The involved field is back: issues in delineating the radiation field in Hodgkin's disease. Ann Oncol. 2002; 13(Suppl 1):7983.

14. Dörffel W, Rühl U, Lüders $H$, et al: Treatment of children and adolescents with Hodgkin lymphoma without radiotherapy for patients in complete remission after chemotherapy: Final results of the multinational trial GPOH-HD95. J Clin Oncol. 2013; 31(12): 1562-1568.

15. Kung FH, Schwartz CL, Ferree CR, et al. POG 8625: A randomized trial comparing chemotherapy with chemoradiotherapy for children and adolescents with Stages I, IIA, IIIA1 Hodgkin Disease: A report from the Children's Oncology Group. J Pediatr Hematol Oncol. 2006; 28(6):362-368.

16. Rigacci L, Vitolo $U$, Nassi L, et al.: Positron emission tomography in the staging of patients with Hodgkin's lymphoma. A prospective multicentric study by the Intergruppo Italiano Linfomi. Ann Hematol. 2007; 86:897-903.

17. Erturk SM, Van den Abbeele AD: Role of $\mathrm{PET} / \mathrm{CT}$ scanning in initial and post-treatment assessment of Hodgkin disease. J Natl Compr Canc Netw. 2008; 6: 623-632.

18. Hutchings $M$, Loft $A$, Hansen $M$, et al.: Position emission tomography with or without computed tomography in the primary staging of Hodgkin's lymphoma. Haematologica. 2006; 91: 482-489.

19. Pelosi E, Pregno P, Penna D, et al.: Role of whole-body [18F] fluorodeoxyglucose positron emission tomography/computed tomography (FDG$\mathrm{PET} / \mathrm{CT}$ ) and conventional techniques in the staging of patients with Hodgkin and aggressive non Hodgkin lymphoma. Radiol Med. 2008; 113: 578-590.

20. Hoppe BS, Flampouri S, Su Z et al. (Consolidative involved- node proton therapy for Stage IA-IIIB mediastinal Hodgkin lymphoma: preliminary dosimetric outcomes from a Phase II study. Int J Radiat Oncol Biol Phys. 2012; 83(1): 260267.

21. Tukenova M, Guibout C et al. Role of cancer treatment in long term overall and cardiovascular mortality after childhood cancer. J Clin Oncol. 2010; 28:1308-15.

22. Travis LB, Gospodarowicz M et al. Lung cancer following chemotherapy and radiotherapy for Hodgkin's disease. J Natl Cancer Inst. 2002; 94:182-92. 23. Travis LB, Hill DA et al. Breast cancer following radiotherapy and chemotherapy among young women with Hodgkin disease. JAMA. 2003; 290:465-75.

24. Specht L, Yahalom J, Illidge T et al. Modern radiation therapy for Hodgkin lymphoma: field and dose guidelines from the International Lymphoma Radiation Oncology Group (ILROG). Int J Radiat Oncol Biol Phys. 2014; 89(4): 854-62. 
25. Thar TL, Million RR, Hausner RJ, et al: Hodgkin's disease, stages I and II: Relationship of recurrence to size of disease, radiation dose, and number of sites involved. Cancer. 1979; 43(3):11011105.

26. Keller FG, Castellino SM, Chen I, et al. Results of the AHOD0431 trial of response adopted therapy and salvage strategy for limited stage classical lymphoma: Report From Children Oncology Group. Cancer 2018; 124: 3210-3219.

27. Mauz-Köholz C, hasenclaver D, Dörffell W, et al. Procarbazine free OEPA-COPDAC chemotherapy in boys and standart OPPA-COP in girls have comparable effectiveness in pediatric Hodgkin lymphoma: the GHOH-hd-2002 study. J Clin Oncol 2010; 28(23),36803686.

28. Diehl V, Brillant C, Engert A, et al. HD10: Investigating reduction of combined modality treatment intensity in early stage Hodgkin's lymphoma. Interim analysis of a randomized trial of the German Hodgkin Study Group (GHSG) [Abstract]. J Clin Oncol 2005; 23: 16S-5561.

29. NCCN Clinical Practise Guidelines in Oncology (NCCN Guidelines), Pediatric Hodgkin Lymphoma. NCCN.org. Version 2.2021-October 21,2020

30. Landman-Parker J, Pacquement H, Leblanc T, et al: Localized childhood Hodgkin's disease: Response-adapted chemotherapy with etoposide, bleomycin, vinblastine, and prednisone before lowdose radiation therapy results of the French Society of Pediatric Oncology Study MDH90. J Clin Oncol. 2000; 18(7):1500-1507.

31. Donaldson SS, Hudson MM, Lamborn KR, et al: VAMP and low-dose, involved-field radiation for

Corresponding author e-mail: faikcetindag@gmail.com

Orcid ID

Mehmet Faik Çetindağ 0000-0003-3404-8144 children and adolescents with favorable, early-stage Hodgkin's disease: Results of a prospective clinical trial. J Clin Oncol. 2002; 20(14): 3081-3087.

32. NCCN Clinical Practise Guidelines in Oncology (NCCN Guidelines), Hodgkin Lymphoma. NCCN.org. Version 2.2 020 April.

33. Hasenclever D, Diehl V: A prognostic score for advanced Hodgkin's disease. International Prognostic Factors Project on Advanced Hodgkin's Disease. N Engl J Med. 1998; 339(21): 1506-1514.

34. Hutchinson RJ, Fryer CJ, Davis PC, et al: MOPP or radiation in addition to $A B V D$ in the treatment of pathologically staged advanced Hodgkin's disease in children: results of the Children's Cancer Group Phase III Trial. J Clin Oncol. 1998; 16(3):897-906.

35. Ferme $C$, Eghbali $H$, Hagenbeek $A$, et al. MOPP/ABV hybrid and irradiation in unfavorable supradiaphragmatic clinical stages III Hodgkin's disease. Comparison of three treatment modalities. Preliminary results of the EORTC-GELA H8U randomized trial in 995 patients. Blood. 000; 96: A576. 36. Fabian CJ, Mansfield CM, Dahlberg $S$, et al: Low-dose involved field radiation after chemotherapy in advanced Hodgkin disease. A Southwest Oncology Group randomized study. Ann Intern Med. 1994; 120(11): 903-912.

37. Poen JC, Hoppe RT, Horning SJ: High-dose therapy and autologous bone marrow transplantation for relapsed/refractory Hodgkin's disease: The impact of involved field radiotherapy on patterns of failure and survival. Int J Radiat Oncol Biol Phys. 1996; 36(1):3-12..

Doi: $10.5505 /$ aot.2021.82473 